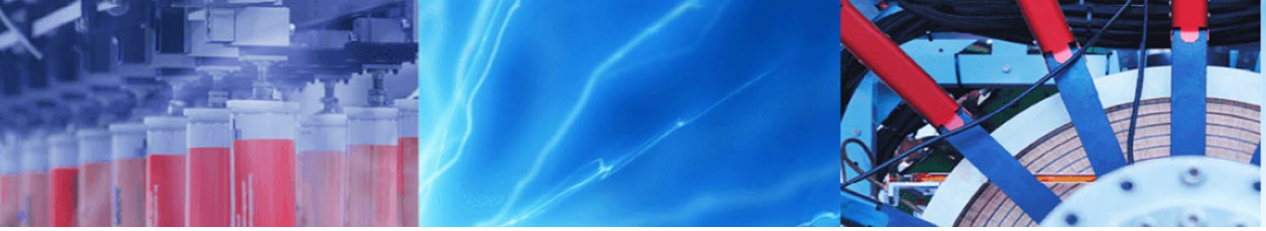

Research Article

\title{
Influence of process conditions and effect of functionalization in inducing time dependent polymorphic states in single walled carbon nanotube incorporated poly(vinylidene fluoride)
}

\author{
Rinu Elizabeth Roy ${ }^{1}$ K. P. Vijayalakshmi ${ }^{2}$ S. Bhuvaneswari' ${ }^{2}$ R. S. Rajeev ${ }^{1}$ (I)
}

C Springer Nature Switzerland AG 2019

\begin{abstract}
Poly(vinylidene fluoride) (PVDF) based composites were prepared using the compatibilizing properties of optimally functionalized single walled carbon nanotubes (SWCNTs). Our previous studies revealed that acid treatment of SWCNTS for $4 \mathrm{~h}$ (FSWCNT-4) incorporates maximum concentration of $-\mathrm{COOH}$ functional groups on nanotube surface with least defects. Therefore, PVDF-SWCNT composites were prepared by dispersing FSWCNT-4 in PVDF through ultrasonication. Here time of ultrasonication controls the crystallization of the polymer either in the electroactive $\gamma$ phase or in the nonelectroactive a phase. $\gamma$ polymorphic state is easily obtained with very low concentration of FSWCNT-4 followed by ultrasonication for just $5 \mathrm{~min}$. The chemical composition of the composites is studied using X-ray photoelectron spectroscopy confirming the inclusion of nanotubes in PVDF. Computational analysis explained the role of ultrasonication in providing the required energy for the transformation from a phase to $\gamma$ phase apart from establishing the favourable site of interaction of PVDF with FSWCNT-4. The micrographs of the composite showed scrolled lamellar features of $\gamma$ phase morphology. PVDF-FSWCNT-4 composites showed 54\% higher capacitance compared to its unfilled counterpart with significant improvement in mechanical properties due to stronger interactions between $\mathrm{H}$ atom with positive charge in PVDF and "O" atom with $\pi$ orbital in FSWCNT-4.
\end{abstract}

Keywords Poly(vinylidene fluoride) $\cdot$ Single walled carbon nanotube $\cdot$ Functionalization $\cdot$ Gamma phase $\cdot$ Polymorphism

\section{Introduction}

Recently we have demonstrated through various characterization techniques that an optimum extent of open end functionalization inducing minimum damage to single walled carbon nanotubes (SWNCTs) is obtained when the nanotubes are functionalized for $4 \mathrm{~h}$ beyond which excessive damage to the nanotube occurs making them unsuitable for practical purposes [1]. At the same time, functionalization for lower extent of time is not conducive enough to attach required number of functional groups for proper interaction with various polymer matrices. In order to validate the optimization of functionalization time, $4 \mathrm{~h}$ functionalized nanotubes were incorporated into various polymeric matrices including vinyl terminated polydimethylsiloxane [2], fluorosilicone polymers [3] and poly (vinylidene fluoride) (PVDF). Our studies on optimally functionalized SWCNT incorporated PVDF not only resulted in validating the optimization of SWCNT functionalization, it also produced some interesting results with reference to the polymorphism of PVDF, which are described in the paper. Electronic supplementary material The online version of this article (https://doi.org/10.1007/s42452-019-0862-0) contains
supplementary material, which is available to authorized users.

$\triangle$ R. S. Rajeev, rs_rajeev@vssc.gov.in | ${ }^{1}$ Polymers and Special Chemicals Division, Vikram Sarabhai Space Centre, Thiruvananthapuram, Kerala 695022, India. ${ }^{2}$ Analytical and Spectroscopy Division, Vikram Sarabhai Space Centre, Thiruvananthapuram, Kerala 695022, India.

SN Applied Sciences (2019) 1:978 | https://doi.org/10.1007/s42452-019-0862-0

Received: 12 March 2019 / Accepted: 28 June 2019 / Published online: 5 August 2019 
PVDF in its native state exists in non-polar a phase. For using the polymer for varied applications, it is required to restrain the non-polar phase and increase its polar forms. In order to improve its polar phase, one of the methods is the use of external nucleating agents such as nanofillers especially those capable of providing high aspect ratio templates [4-7]. Among all the nanofiller used for the preparation of PVDF composites, carbon nanotube (CNTs) is considered as ideal reinforcing filler because of its excellent mechanical, electrical and thermal properties [8]. Polymer/CNT composites offer improvement in stiffness, modulus, electrical conductivity and lower coefficient of thermal expansion at a relatively low CNT concentration [9]. Also, a very low percolation threshold can be achieved in the composite due to the high aspect ratio of CNTs [10]. On the other hand, highly hydrophobic pristine CNTs are found to have weaker compatibility with PVDF diminishing its capability as an effective nucleating agent for the generation of polar phase in PVDF. Modification of CNT surface through a variety of functional groups, especially acid groups so as to have proper interaction with PVDF chains, also induces the formation of polar phase in the composites [11]. Studies have shown that introduction of carbonyl groups $(C=O)$ on the filler surface results in good dispersion as a result of strong contact among the $\mathrm{CF}_{2}$ functionality in PVDF and the carbonyl functionality on the reactive ends of CNT [7]. This efficient interaction aids in the growth of $\beta$ phase along with enhancement in mechanical, thermal and electrical properties of these composites.

An established technique for the formation of polar phase in PVDF with the addition of CNTs is ultrasonication [12]. It is the most widely used technique to achieve nanolevel dispersion of nanomaterials in a polymer matrix. The crystallization mechanism for the induction of polar phase in PVDF with the addition of CNTs through the process of ultrasonication was explained by Manna et al. [8]. According to them, the surface of CNTs having zigzag " $C$ " atoms is found to be equivalent with all trans configuration of polar $\beta$ phase of PVDF resulting in crystallization to the polar phase. By using density functional theory calculations, Yu et al. [13] explained that as a result of ultrasonication, the non-polar phase with TGTG configuration can be changed to polar phase with TTTT configuration. The polar configuration thus attached on CNTs will result in an efficient crystallization of PVDF. Ultrasonication induced phase changes in neat PVDF matrix is also reported by Qu et al. [14]. The intense sound waves generated during ultrasonication create cavitation in the medium [15] which is capable of causing crystalline changes in the PVDF matrix. Therefore, it is interesting to study the influence of ultrasonication on the phase changes and associated properties of optimally functionalized SWCNT (FSWCNT) incorporated PVDF matrix. This is because; the interfacial interaction between PVDF and functionalized nanotube will undergo changes during the crystallization of the polymer matrix.

Though a good deal of work on composites based on PVDF and multi-walled CNTs (MWCNTs) $[16,17]$ as well as PVDF and single-walled CNTs (SWCNTs) $[18,19]$ have been reported, to the best of our knowledge, a systematic investigation using FSWCNTs, where the optimization protocols are well documented [1], is scarce, especially the interaction mechanism between FSWCNTs and PVDF. In addition, even though reports are available on phase morphology of ultrasonicated PVDF-SWCNT composites [20], the effect of processing parameters such as duration of ultrasonication, extent of functionalization of CNT, concentration of the nanotube in the matrix etc. on the phase morphology and associated properties of PVDF-FSWCNT composites are not yet reported.

In the present study, processing of PVDF using FSWCNT was done by preparing composites with different ultrasonication time and compared them with a composite prepared without ultrasonication. Computational analysis and Raman spectroscopy were utilized to investigate the difference in molecular level interaction between PVDF and FSWCNT. The PVDF composites based on FSWCNT showed prominent changes in the mechanical and electrical properties at an optimum duration of ultrasonication. The study addresses the need for an efficient approach for the preparation of PVDF nanocomposite films for the effective transfer of properties of the filler to the matrix. Finally, the effects of different nanotube concentrations were studied in order to achieve maximum electroactive polymorphic phase with superior mechanical and electrical properties.

\section{Experimental}

\subsection{Materials}

SWCNT with diameters of $0.7-1 \mathrm{~nm}$ and lengths of $2-5 \mu \mathrm{m}$ were obtained from South West Nano Technologies. Conc. $\mathrm{HNO}_{3}(69 \% \mathrm{w} / \mathrm{w})$ from Merck was used for the oxidation of SWCNT. For the preparation of composites, PVDF was purchased from Alfa Aesar and the solvent used was Dimethyl acetamide (DMAC) which was procured from Finar.

\subsection{Functionalisation of SWCNTs}

The functionalization procedure as well as characterization of SWCNTs adopted for the present investigation has already been reported [1]. SWCNT functionalized using conc. $\mathrm{HNO}_{3}$ for $4 \mathrm{~h}$ is chosen as the modified filler 
for the preparation of PVDF composites and it is denoted as FSWCNT- 4 in the rest of the paper. As elaborated in [1], FSWCNT-4 has got the maximum concentration of functional groups viz. carboxyl $(\mathrm{COOH})$, hydroxyl $(\mathrm{C}-\mathrm{OH})$ and carbonyl $(\mathrm{C}=\mathrm{O})$ functionalities with least defects as reported in the paper. PVDF/FSWCNT-4 composites were prepared with an aim to prove the utility of our optimized filler (FSWCNT-4) in the crystallization as well as electroactive and mechanical properties of PVDF.

\subsection{Preparation of PVDF composites through air drying}

For the preparation of PVDF-FSWCNT-4 composites, initially FSWCNT-4 was dispersed in $20 \mathrm{ml} \mathrm{DMAc}$ by ultrasonication for $15 \mathrm{~min}$ to get a stable colloidal dispersion. It was followed by addition of PVDF powder $(2 \mathrm{~g})$ into the stable dispersion and the mixture was stirred at $60^{\circ} \mathrm{C}$ until PVDF powder is completely dissolved in DMAc. To obtain self polarized and high quality PVDF/FSWCNT-4 composites, the mixture was ultrasonicated for different time intervals viz. 5, 15, 45, 60 and 120 min using Hielscher industrial ultrasonic processor model UP1000hd (1000 W, $20 \mathrm{kHz}$, horn $\varnothing 34 \mathrm{~mm}$, amplitude 25 micron) using Bs $2 \mathrm{~d} 18$ sonotrode. Each ultrasonicated PVDF/FSWCNT-4 mixture was then poured on a glass plate using doctor blade (by adjusting the gap to get films of $50 \mu \mathrm{m}$ thickness) and then air dried at $70^{\circ} \mathrm{C}$ for $2 \mathrm{~h}$. For a comparison, a composite without ultrasonication has also been prepared and cast as above. All the composite films were prepared with $0.1 \mathrm{wt} \%$ of FSWCNT-4 as it is already reported by Achabya et al. [21] that for nucleating all PVDF chains into electroactive phase structure, only $0.1 \mathrm{wt} \%$ of the filler are required. In order to study the effect of different concentrations of FSWCNT-4 on the electroactive phase content, films were prepared with 0.01 and 0.05 wt $\%$ of FSWCNT-4 as well.

\subsection{Characterization}

For the determination of phase changes in PVDF and its nanocomposites, FT-IR analysis in ATR mode was done using Perkin Elmer Spectrum GX FTIR spectrophotometer. The wavelength range of the samples was $4000-550 \mathrm{~cm}^{-1}$ and the spectral resolution was $2 \mathrm{~cm}^{-1}$. Our PVDF and its nanocomposites contain both $\alpha$ and $\gamma$ phases. Hence, the relative fraction of $\gamma$ phase, $[F(\gamma)]$ in PVDF is calculated from FTIR spectrum based on Eq. (1)

$\mathrm{F}(\gamma)=\frac{\mathrm{A} \gamma}{(\mathrm{K} \gamma \mid \mathrm{K} \alpha) \mathrm{A} \alpha+A \gamma}$

where $A a$ and $A \gamma$ represents the absorbance at 763 and $833 \mathrm{~cm}^{-1} ; \mathrm{Ka}$ and $\mathrm{K} \gamma$ relates to the coefficient of absorption at particular wave numbers having values of 0.365 and $0.150 \mu^{-1}[22,23]$.

Further, the phase changes were analyzed using a Bruker D8 Discover X-ray diffractometer. Raman spectral studies of the samples in this work have been conducted using WITec alpha 300R Confocal Raman microscope with a laser source of $532 \mathrm{~nm}$. For the determination of the diameters of nanotubes from Raman spectroscopy, the following equation was used [24],

$\omega_{\mathrm{RBM}}=\frac{223.5}{d(\mathrm{~nm})}+12.5$

where $\left(\omega_{\mathrm{RBM}}\right)$ denotes the Raman shift.

The chemical composition of PVDF and its nanocomposite was studied using X-ray photoelectron spectroscopy (XPS) which was carried out with Multilab 2000 (Thermo Fischer Scientific) using Al-K radiation. The crystallization studies of PVDF and their nanocomposites were done using TA Instruments DSC model Q20 in an inert atmosphere using a heating and cooling rate of $5^{\circ} \mathrm{C} / \mathrm{min}$. Nova Nano SEM 450 was used to determine the morphology of PVDF and its nanocomposites under an accelerating voltage of $5 \mathrm{kV}$ and $20 \mathrm{kV}$. A Leica Sputter Coating Equipment with model name EMSCD005 was used for gold coating the samples before morphological analysis. Morphology was studied using atomic force microscope (AFM) as well using Agilent 5500 scanning probe microscope in contact mode. Mechanical properties of the films and composites were measured using INSTRON 5569 Universal Testing Machine (UTM) with at least 3 samples of each composite as per ASTM D-882. The cross head speed of UTM was set as $50 \mathrm{~mm} / \mathrm{min}$ and the gauge length used is $80 \mathrm{~mm}$. A TEGAM $3550 \mathrm{LCR}$ meter was used to determine the capacitance of films as per ASTM D-257 method. Capacitance was measured at a frequency of $1 \mathrm{kHz}$ and an applied voltage of $500 \mathrm{~V}$ and the temperature and relative humidity were $23^{\circ} \mathrm{C} \pm 1{ }^{\circ} \mathrm{C}$ and $60 \% \pm 10 \%$.

\subsection{Computational studies}

PM6 level of semi empirical method as implemented in Gaussian 09 suite of program $[25,26]$ was used to optimize all the structures of PVDF, FSWCNT-4 and their complexes. Since, PVDF exists in two different phases' viz. $a$ and $\gamma$, both phases were constructed using twenty repeating units of vinylidene fluoride. In order to confirm the nonexistence of any imaginary frequency, vibrational frequency analysis was also carried out. FSWCNT was constructed using arm chair $(6,6)$ configuration having two different functionalities viz. carboxyl and hydroxyl groups. The minimized structures of PVDF ( $a$ and $\gamma$ ) as well as FSWCNT were included in the supporting information. 


\section{Results and discussion}

\subsection{Effect of ultrasonication on the phase morphology of optimally functionalized SWCNT incorporated PVDF}

To study the effect of extent of ultrasonication, PVDF nanocomposites with $0.1 \mathrm{wt} \%$ of FSWCNT-4 were ultrasonicated for different time intervals followed by air drying at $70^{\circ} \mathrm{C}$. For a comparison a composite without ultrasonication has also been prepared. The designation and conditions of ultrasonication for different PVDF nanocomposites are given in Table 1. From the FTIR spectra of PVDF/FSWCNT-4 composites prepared without and with ultrasonication (Fig. 1), it is observed that the time of ultrasonication affects the phase morphology of FSWCNT incorporated composite. PFSn-0.1-0 shows the presence of peaks at $1208,976,795,763$ and $613 \mathrm{~cm}^{-1}$, which are characteristics of the non-polar a phase [27]. On the other hand, films ultrasonicated for $5,15,45,60$ and 120 min show progressive decrease in intensity of the peaks characteristic of the non-polar a phase and progressive increase in the intensity of the peaks corresponding to the electroactive $\gamma$ phase which are observed at wave numbers, 812,833 and $1231 \mathrm{~cm}^{-1}$ for these polymer composites [28]. Interestingly, PFSn-0.1-5 show complete disappearance of peaks corresponding to a phase implying that ultrasonication for 5 min produces predominantly $\gamma$-phase in the PVDFFSWCNT-4 composites.

The percentage of $\gamma$ phase in PVDF/FSWCNT-4 composites calculated using Eq. (1) is given in Table 1. It is evident that the percentage of $\gamma$ phase is only 34 when the composite is not subjected to ultrasonication. However, ultrasonication induces phase changes and $\gamma$ phase dominates in all such composites. Time of ultrasonication is also having significant effect on the phase conversion. $\gamma$ phase is maximum (95\%) for the polymer which is subjected to

Table 1 Identification of films, time of ultrasonication $\left(T_{U S}\right)$ and percentage of $\gamma$ phase of the prepared composites

\begin{tabular}{lcl}
\hline Identification of the films $^{\text {a }}$ & $T_{\text {US }}^{\mathrm{a}}(\mathrm{min})$ & $\begin{array}{l}\text { Percentage of } Y \\
\text { phase, }\left[\mathrm{F}_{Y}(\%)\right]\end{array}$ \\
\hline PFSn-0.1-0 & 0 & 34 \\
PFSn-0.1-5 & 5 & 95 \\
PFSn-0.1-15 & 15 & 78 \\
PFSn-0.1-45 & 45 & 77 \\
PFSn-0.1-60 & 60 & 72 \\
PFSn-0.1-120 & 120 & 71 \\
\hline
\end{tabular}

${ }^{\text {ap }}$ denotes PVDF; FSn functionalized SWCNT (-COOH functionalized for $4 \mathrm{~h}$ ); $\mathrm{n}$ denotes composite; $\mathrm{T}_{\text {US }}$ denotes time of ultrasonication; all compositions contain 0.1 wt $\%$ FSWCNT

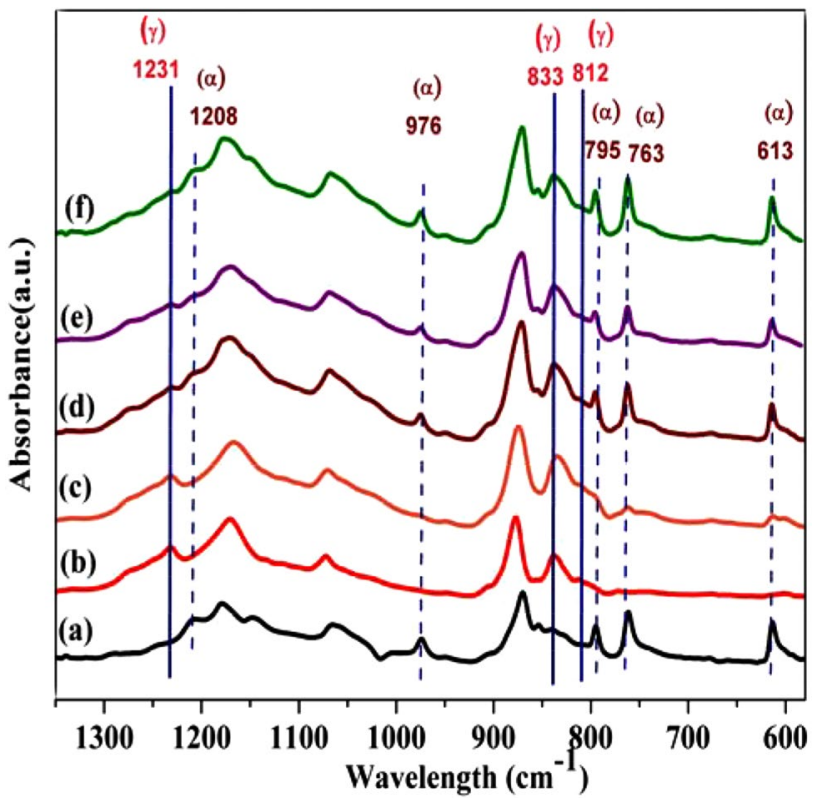

Fig. 1 Overlaid FTIR spectra of PVDF/FSWCNT-4 composites ultrasonicated at different time intervals. (a) PFSn-0.1-0, (b) PFSn-0.1-5, (c) PFSn-0.1-15, (d) PFSn-0.1-45, (e) PFSn-0.1-60 and (f) PFSn-0.1120

only 5 min ultrasonication. Percentage of $\gamma$ phase in the polymer decreases to $78 \%$ when the mixture is ultrasonicated for $15 \mathrm{~min}$. Further increase in time of ultrasonication does not significantly changes the $\gamma$ phase content in the polymer. It is already reported by us that when PVDF alone is subjected to different extent of ultrasonication, in order to get predominantly $\gamma$ phase, the polymer needs to be ultrasonicated for a minimum of $60 \mathrm{~min}$ [29]. However, presence of only $0.1 \mathrm{wt} \%$ FSWCNT-4 causes similar phase change in just $5 \mathrm{~min}$. The percentage of $\gamma$ phases of different PVDF films and PVDF-FSWCNT-4 nanocomposites, ultrasonicated for different extent of time are shown in ESI. The unfilled PVDF films ultrasonicated for different extent of time are identified as $\mathrm{P}-0, \mathrm{P}-5, \mathrm{P}-15, \mathrm{P}-45, \mathrm{P}-60$ and $\mathrm{P}-120$ for the time of ultrasonication ( $\left.T_{U S}\right) 0,5,15,45,60$ and 120 min respectively.

From the Figure shown in supporting information, it is evident that in order to get $\gamma$ phase content more than $90 \%$, unfilled PVDF solution needs to be ultrasonicated for $60 \mathrm{~min}$ whereas $95 \%$ y phase content can be achieved within 5 min if $0.1 \%$ FSWCNT-4 is present in PVDF matrix. The crystallization into a polar $\gamma$ phase is due to an intimate contact among the polar functional groups of FSWCNT-4 as well as the dipole moments of PVDF [30]. Ultrasonication provides the required energy for these ion-dipole interactions which results in a perfect arrangement of PVDF chains into a trans configuration leading to the formation of polar $\gamma$ phase [13]. Clearly, the composite 
prepared without ultrasonication doesn't have enough energy for the orientation of PVDF into trans conformation, thus crystallizing mainly in the a phase. However, optimum time of ultrasonication (5 min, in this case of PVDF-FSWCNT-4 composite), creates sufficient energy for the chain orientation, thus creating $95 \%$ p phase in the polymer. Increasing the time of ultrasonication reduces the $Y$ phase content presumably because of the initiation of chain damage as well as breakage of CNTs due to the high energy created [31]. Still, the $\gamma$ phase content in PVDF/FSWCNT-4 ultrasonicated for 15, 45, 60 and $120 \mathrm{~min}$ is $78 \%, 77 \%, 72 \%$ and $71 \%$ respectively, which is significantly higher than that in unsonicated composite, PFSn0.1-0. Slightly higher $\gamma$ phase content is evident for PVDF containing no CNTs, which are ultrasonicated for 15, 45 and 60 min compared to PVDF/FSWCNT-4 composites. This shows that there is an optimum combination of energy created by ultrasonication and presence of nucleating agent, which together act to get the maximum electroactive phase in PVDF/FSWCNT-4, which is $5 \mathrm{~min}$ in this case. Further increase in time induces necessary morphological changes in the polymer matrix to retain the $\gamma$ phase; however, the associated damage of CNT at higher extent of ultrasonication may not help in sufficient nucleation of the crystalline phase so that PVDF/FSWCNT-4 composites have slightly lower $\gamma$ phase content as extent of ultrasonication increases.

The XRD patterns of neat PVDF (P-0), PFSn-0.1-0 and PFSn-0.1-5 are shown in Fig. 2. The patterns confirm that P- 0 crystallizes in the a phase, with characteristic peaks at $2 \theta$ values $17.7^{\circ}, 18.4^{\circ}, 19.9^{\circ}$ and $26.6^{\circ}$ corresponding to (100), (020), (110) and (021) crystal planes respectively. PFSn-0.1-0 also crystallizes in a phase having distinctive peaks of $2 \theta$ at $17.7^{\circ}, 18.4^{\circ}, 20.3^{\circ}$ as well as $26.6^{\circ}$ corresponding to (100), (020), (201) and (021) crystal planes respectively while PFSn-0.1-5 shows characteristic peaks of $\gamma$ phase with reflections at $18.5^{\circ}(020)$ and $20.3^{\circ}(101)$ [32]. These observations are in agreement with FT-IR results. A similar XRD pattern was also observed for PVDF nanocomposites prepared with different clay structures processed by solvent casting and melt crystallization technique [30]. Depending on the melting temperature the nanocomposites recrystallizes in polar $\gamma$ phase or non-polar a phase.

Spectroscopic results confirm that with the addition of 0.1 wt $\%$ of FSWCNT-4 followed by a short duration ultrasonication for $5 \mathrm{~min}$, phase change from non-polar to polar phase occurs in PVDF. Hence, it is clear that the presence of FSWCNT-4 as a nucleating agent causes a favourable interaction and conformational change in PVDF. To confirm the incorporation of nanotubes into PVDF, chemical composition of the PVDF film and the nanocomposite (PFSn-0.1-5) are analyzed using XPS. The deconvoluted $C_{15}$ high resolution spectra of PVDF and PFSn-0.1-5 are shown in Fig. 3.

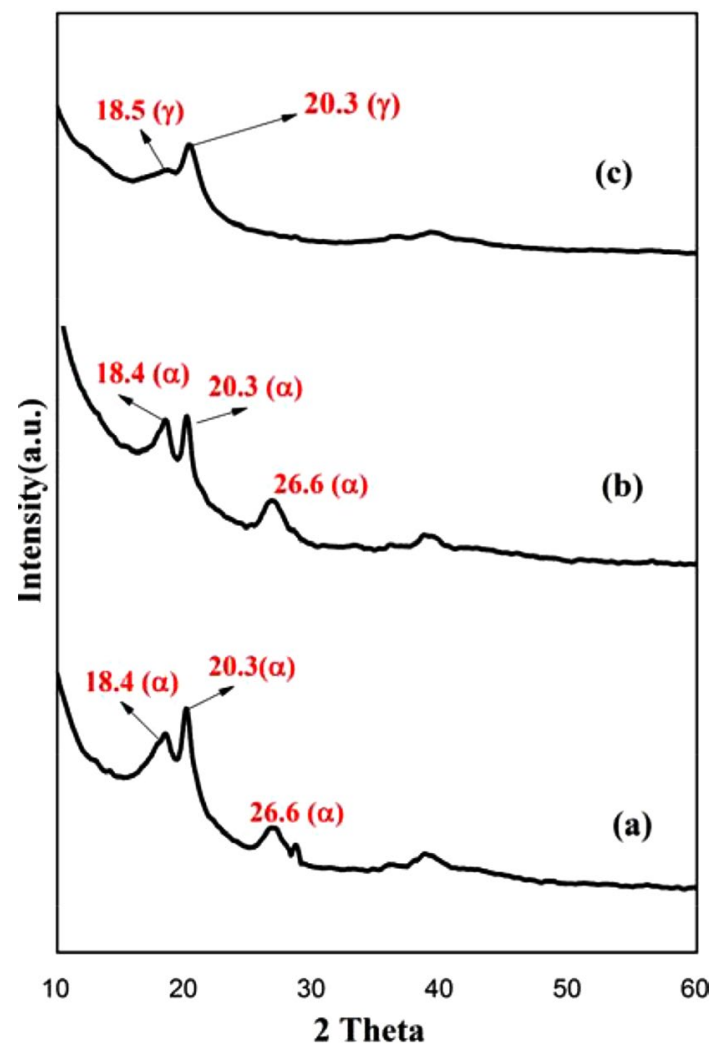

Fig. 2 XRD patterns of (a) P-0, (b) PFSn-0.1-0 and (c) PFSn-0.1-5

PVDF show two dominant peaks at $284.6 \mathrm{eV}$ corresponding to $\mathrm{CH}_{2}$ species and $289.4 \mathrm{eV}$ of $\mathrm{CF}_{2}$ species $[33,34]$. Inclusion of FSWCNT-4 into the polymer matrix results in the broadening of $C_{1 s}$ profile as seen in Fig. $4 \mathrm{~b}$. Addition of functionalized nanotubes results in the attachment of oxygen containing functional groups with a shift in the binding energy values to higher level. The $C_{15}$ envelope of PFSn0.1-5 is divided into five regions with two peaks comprising of $\mathrm{CH}_{2}$ and $\mathrm{CF}_{2}$ peaks of PVDF at binding energy values of 284.6 and 290.5 while the remaining peaks corresponds to $\mathrm{sp}^{2} \mathrm{C}=\mathrm{C}(284.6 \mathrm{eV}), \mathrm{C}-\mathrm{OH}(285.5 \mathrm{eV})$ and $\mathrm{COOH}(289.2 \mathrm{eV})$ of FSWCNT-4 [1,35] confirming the efficient incorporation of functionalized nanotubes into the PVDF matrix.

After confirming the chemical composition of the films, the mechanism of formation of $\gamma$ phase in the nanocomposites prepared through ultrasonication is studied using computational analysis. The interactions of both the a phase and $\gamma$ phase conformations of PVDF- FSWCNT was modelled using model compounds constructed out of 20 monomers. The polar $\gamma$ phase conformation of PVDF is the most preferred conformer for binding with FSWCNT as the interaction stabilizes the system by $45 \mathrm{~kJ} / \mathrm{mol}$. On the other hand, the interaction energy of a phase conformation is less than that of $\gamma$ phase conformation with a computed value of $28 \mathrm{~kJ} / \mathrm{mol}$. 
Fig. $3 C_{1 S}$ high resolution deconvoluted spectra of a PVDF and b PFSn-0.1-5
Fig. 4 The interaction of a a phase conformer of PVDF with FSWCNT, $\mathbf{b} \gamma$ phase conformer of PVDF with FSWCNT. The distance is in $\AA$ unit
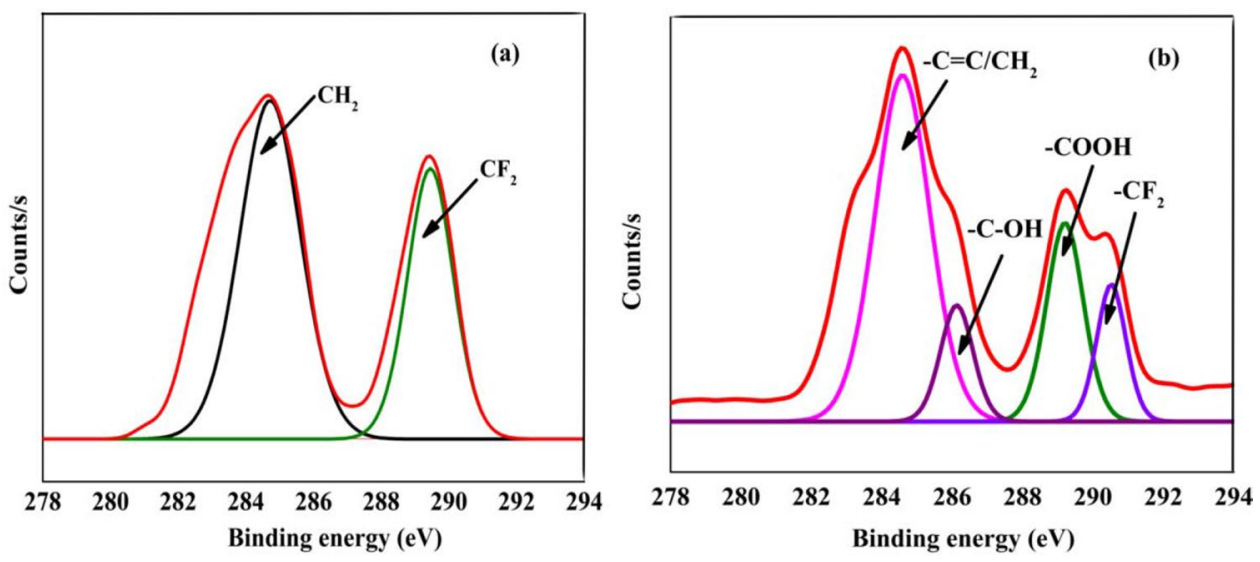

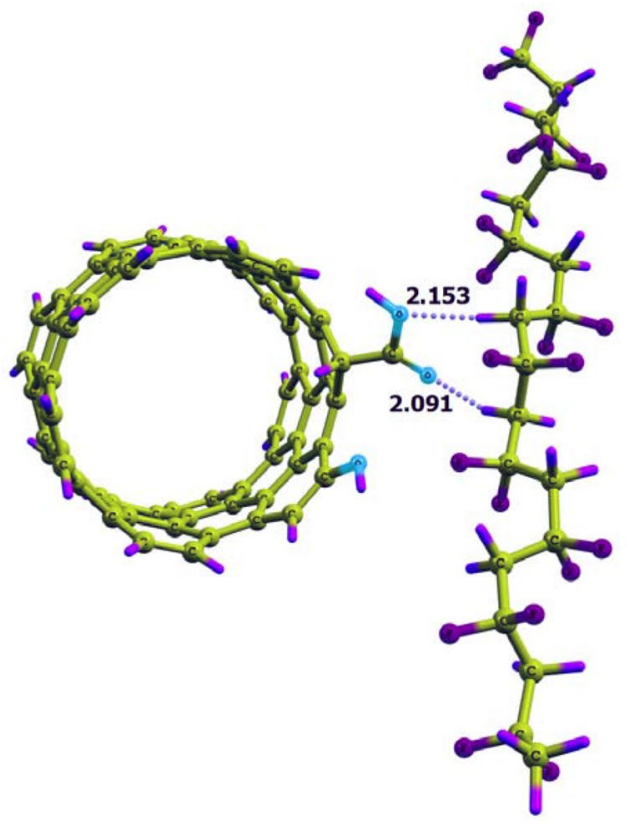

(a)

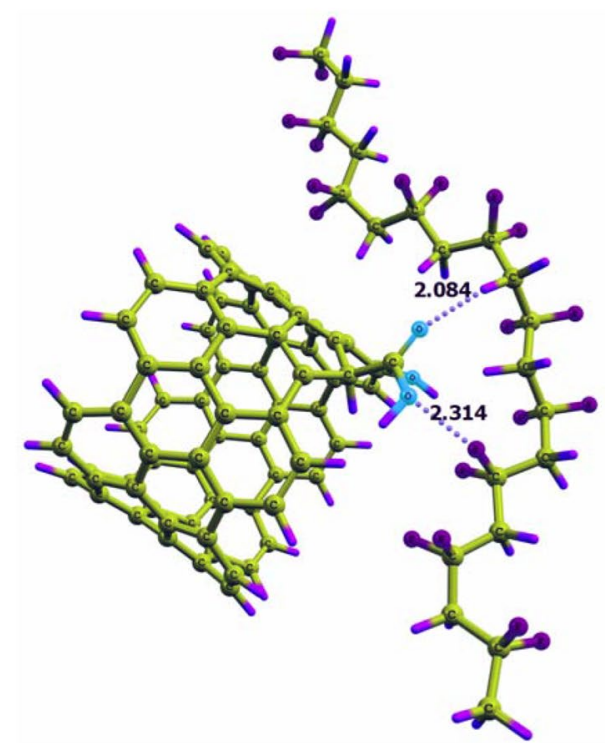

(b)
The exact sites of interaction between the two different conformers of PVDF with FSWCNT are shown in Fig. 4. Figure $4 \mathrm{a}$ depicts the possible sites of interactions between FSWCNT and a conformer of PVDF. The carbonyl "O" of the carboxyl group in FSWCNT interacts with the " $\mathrm{H}$ " of the methylene group in PVDF at an interaction distance of $2.091 \AA$ which forms the major site of interaction while the hydroxyl "O" of the carboxyl group in FSWCNT interacts with methylene " $\mathrm{H}$ " at an interaction distance of $2.153 \AA$.

Similarly, the major sites of interaction between the $\gamma$ conformer of PVDF and FSWCNT was found to be carbonyl "O" of the carboxyl group in FSWCNT with " $\mathrm{H}$ " of the methylene group in PVDF at an interaction distance of $2.084 \AA$ and the hydroxyl "O" of the carboxyl group in FSWCNT with the "F" group in - $\mathrm{CF}_{2}$ at an interaction distance of $2.314 \AA$
(Fig. 4b). As expected, the interaction between carboxyl group in FSWCNT and the methylene group in PVDF is stronger than that with $-\mathrm{CF}_{2}$ group. In addition, it is the carbonyl "O" of the carboxylic group in FSWCNT that interacts much stronger with the $Y$ PVDF than the hydroxyl "O" of the carboxylic group in FSWCNT. These are attributed to the fact that a stronger interaction occurs between $\mathrm{H}$ atom with positive charge in PVDF and " $\mathrm{O}$ " atom with $\pi$ orbital in FSWCNT than between the highly negative " $F$ " atom and "O" atom with $\sigma$ orbital.

Even though it is obvious that the $Y$ phase of PVDF is the preferred site of absorption on the FSWCNT surface, the energy of a phase being lower makes it more stable than the $\gamma$ phase [36] which is also clear from our calculations (ESI). Thus, in the normal state, PVDF exists in its 
non-polar a phase. Only through special treatment like ultrasonication, the high energy $\gamma$ phase can be obtained [13]. Hence, in the unsonicated PVDF/FSWCNT dispersion only a phase exists which is confirmed from various spectroscopic analysis. However, the process of ultrasonication in PVDF/FSWCNT dispersion results in an alteration from non-polar a phase to the polar $y$ phase as confirmed from FTIR and XRD analyses. Under, the extremely severe conditions brought by the process of ultrasonication such as high temperature of $5000 \mathrm{~K}$, a high pressure of $50.6 \mathrm{MPa}$ and rate of heating and cooling greater than $10^{9} \mathrm{~K} / \mathrm{s}$ [15], PVDF in the non-polar state will obtain energy from the ultrasonicated solution and can easily overcome the energy barrier of $45 \mathrm{~kJ} / \mathrm{mol}$ between a phase (TGTG) and $\gamma$ phase (TTTG) configurations transforming into TTTG type chains. Further, the $\gamma$ phase molecular chains get adsorbed on the surface of FSWCNTs which acts as an efficient nucleating agent for the polar $\gamma$ phase.

To rationalize the findings of computational analysis, the interaction of PVDF with FSWCNT-4 is probed using Raman spectroscopy. The electron rich CNTs will interact with an electron deficient molecule which results in the formation of a complex having donor-acceptor features $[37,38]$. In a similar manner, SWCNTs functionalized with carboxylic and hydroxyl groups as in the present study are also electron rich species capable of interacting with electron-deficient molecules in PVDF. To study the interaction among FSWCNT-4 and PVDF, Raman spectroscopy was employed using $532 \mathrm{~nm}$ wavelength source.

The Raman spectra of radial breathing mode (RBM) region of FSWCNT-4 and PFSn-0.1-5 are shown in Fig. 5. After normalization to the most intense peak, the collected spectra are separated and offset vertically for clarity. For FSWCNT-4, two peaks at 188 and $260 \mathrm{~cm}^{-1}$ are observed

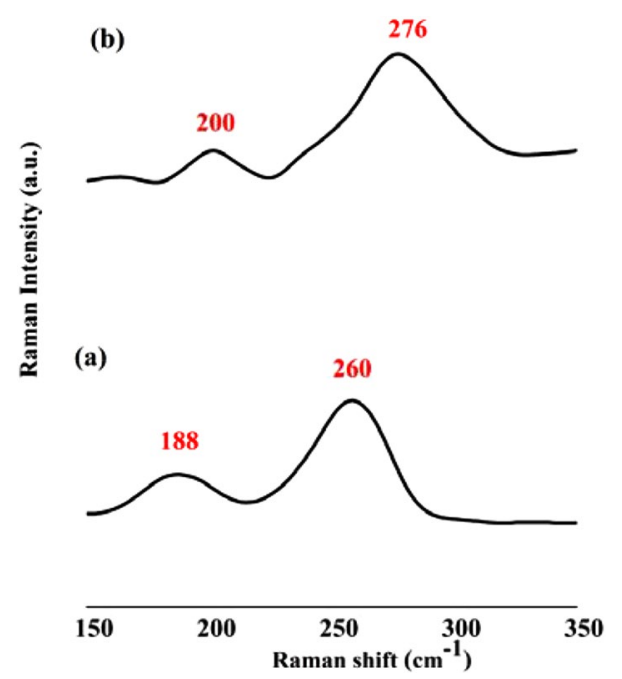

Fig. 5 Raman spectra of RBM region in a FSWCNT-4 and b PFSn$0.1-5$ while for PFSn-0.1-5 both the low wave number peaks shift to 200 and $276 \mathrm{~cm}^{-1}$ respectively. This peak shift in the polymer is an indication of the interaction between PVDF and FSWCNT-4. Similar changes in the RBM frequencies were observed when SWCNTs containing iron nanoparticles were added to PVDF [37].

Table 2 shows the Raman shift values $\left(\omega_{\text {RBM }}\right)$ and corresponding diameters (d) of FSWCNT-4 and the composite film. Our studies on SWCNTs functionalized for different extent of time using the Kataura plot, which describes the relationship between transition energies and nanotube diameter, show that the FSWCNT-4, consists of tubes of primarily two types of diameters, $1.27 \mathrm{~nm}$ and $0.90 \mathrm{~nm}$ as probed by the $532 \mathrm{~nm}$ laser source [1]. Those nanotubes are metallic in nature. When FSWCNT-4 is incorporated in PVDF matrix, the diameters of nanotubes are found to be 1.19 and $0.85 \mathrm{~nm}$ as determined using Eq. (2). In view of the inversely proportional correlation between diameter and RBM frequency, the RBM upshift in PFSn-0.1-5, suggests that PVDF may have different diameter selectivity for FSWCNT-4 during the formation of composites. Rice et al. [39] studied the dispersion behaviour of as prepared SWCNT powders with linear conjugated polymers where the RBM showed an upshift in SWCNT and polymers in comparison to pristine SWCNT powder which is attributed to different diameter selectivity.

To study the metallic behaviour of PFSn-0.1-5, the line shape of G-band, which is also known as the graphitic band was studied and is shown in Fig. 7. The $G$ band at $1580 \mathrm{~cm}^{-1}$, which is the most intensive mode of CNTs, provides useful information regarding its electronic nature (i.e. semiconducting or metallic). It comprises of two different peaks, a lower frequency known as $\mathrm{G}^{-}$and a higher frequency known as $\mathrm{G}^{+}$. The $\mathrm{G}^{-}$peak relates to vibrations in circumferential route while $\mathrm{G}^{+}$peak relates to vibrations in the route of tube axis. $\mathrm{G}+$ and $\mathrm{G}$ - are observed for semiconducting nanotubes while a broad and asymmetric profile with merged $\mathrm{G}+$ and $\mathrm{G}-$ corresponds to metallic nanotubes called the Breit-Wigner-Fano (BWF) lineshape. G-band with symmetric line shape without two components is observed in case of mixture of tubes [40].

Table 2 Raman shift $\left(\omega_{\mathrm{RBM}}\right)$ and corresponding diameters $(d)$ of FSWCNT-4 and composite film

\begin{tabular}{lll}
\hline Sample & Raman shift, $\omega_{\text {RBM }}\left(\mathrm{cm}^{-1}\right)$ & $\begin{array}{l}\text { Diam- } \\
\text { eter, d } \\
(\mathrm{nm})\end{array}$ \\
\hline FSWCNT-4 & 188 & 1.27 \\
PFSn-0.1-5 & 260 & 0.90 \\
& 200 & 1.19 \\
& 276 & 0.85 \\
\hline
\end{tabular}


As shown in Fig. 6, an up-shift of $28 \mathrm{~cm}^{-1}$ of Breit-Wigner-Fano (BWF) line shape $\left(\mathrm{G}^{+}\right.$peak) around $1592 \mathrm{~cm}^{-1}$ and a $\mathrm{G}^{-}$peak around $1528 \mathrm{~cm}^{-1}$ is observed for PFSn-0.1-5 as compared to FSWCNT-4. The up-shift and width change of G-band is evidence on the interaction between PVDF chain and FSWCNT-4. Rao et al. reported a significant shift in the G-band to higher and lower frequencies are observed when CNTs are functionalized using electron deficient groups like bromine and electron rich groups like potassium [41]. In this study, as confirmed from computational analysis a stronger interaction occurs between $\mathrm{H}$ atom with positive charge in PVDF and "O" atom with $\pi$ orbital in FSWCNT resulting in an upshift of G-band.

Figure 6 also shows a D-band up-shift of $15 \mathrm{~cm}^{-1}$ for PFSn-0.1-5 compared to FSWCNT-4; that is from $1320 \mathrm{~cm}^{-1}$ for FSWCNT-4 to $1335 \mathrm{~cm}^{-1}$ for PFSn-0.5-5. The composite with characteristic BWF line shape show an enhancement in D-band intensity as compared to FSWCNT-4 which is attributed to the processing of composites by ultrasonication resulting in disruption of the structure of FSWCNT-4

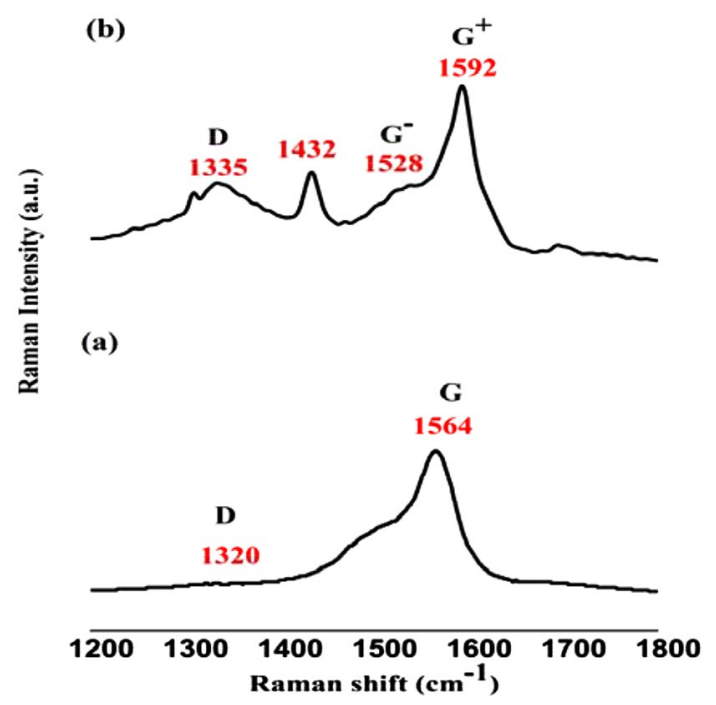

Fig. 6 Raman spectra of G band and D band region in a FSWCNT-4 and $\mathbf{b}$ PFSn-0.1-5 and introduction of more defects in the nanotubes. As defects increase on the nanotube surface, D-band intensity will correspondingly increase.

The 2D bands of FSWCNT- 4 and PFSn-0.1-5 are shown in ESI. It is extremely responsive to the compactness of electronic states in case of resonant SWCNTs [40]. The 2D band frequency of FSWCNT-4 is observed at $2620 \mathrm{~cm}^{-1}$ while a shift towards higher frequency for PFSn-0.1-5 is observed which is at $2652 \mathrm{~cm}^{-1}$. The peak shift is an indication of the change in the diameter of nanotubes when incorporated in PVDF matrix, as observed in the RBM region. Further, the molecular level interactions are confirmed by changes in the Raman spectra in the $\mathrm{C}-\mathrm{H}$ stretch region of P-0 and PFSn-0.1-5 (ESI). It is observed that the $\mathrm{C}-\mathrm{H}$ stretch modes of P-0 is shifted from 2983 to 2975 and from 3024 to $3016 \mathrm{~cm}^{-1}$ in PFSn-0.1-5; moreover, the intensity of peak at $3016 \mathrm{~cm}^{-1}$ of PFSn-0.1-5 is lowered in comparison to P-0. All these observations indicate strong interaction between PVDF and FSWCNT-4 [42].

The phase change in PVDF with the incorporation of optimally functionalized SWCNTs causes morphological changes as well. FESEM images of the composites are given in Fig. 7. The FESEM image of unsonicated composite, PFSn-0.1-0 (Fig. 7a) shows spherulites with a porous morphology and formation of dendrites at some points, confirming the crystallization of non-polar a phase [43, 44]. When the mixture is ultrasonicated for $5 \mathrm{~min}$, as can be seen in Fig. 7b, the composite, PFSn-0.1-5 adopts an interesting structural design where an extremely curled morphology is observed. Vaughan et al. [45] observed such kind of scrolled lamellar morphology during the melt crystallization of PVDF films at temperatures higher than $165^{\circ} \mathrm{C}$, which were characteristics of polar $\gamma$ phase. When such films were viewed along the spherulite radius, a highly curved profile of lamellae was observed similar to those observed in 1-polybutene which was crystallized from amyl acetate [46]. Thus, spherulites under radial view consist of an array of rounded cells and each of these cells is packed with lamellae having extremely curled scroll like morphology. Similarly, we also observe the formation of scrolled lamellar features of $\gamma$ phase
Fig. 7 FESEM micrographs of a PFSn-0.1-0 and b PFSn-0.1-5 with scale bar $=5 \mu \mathrm{m}$ and $\times 10,000$ magnification
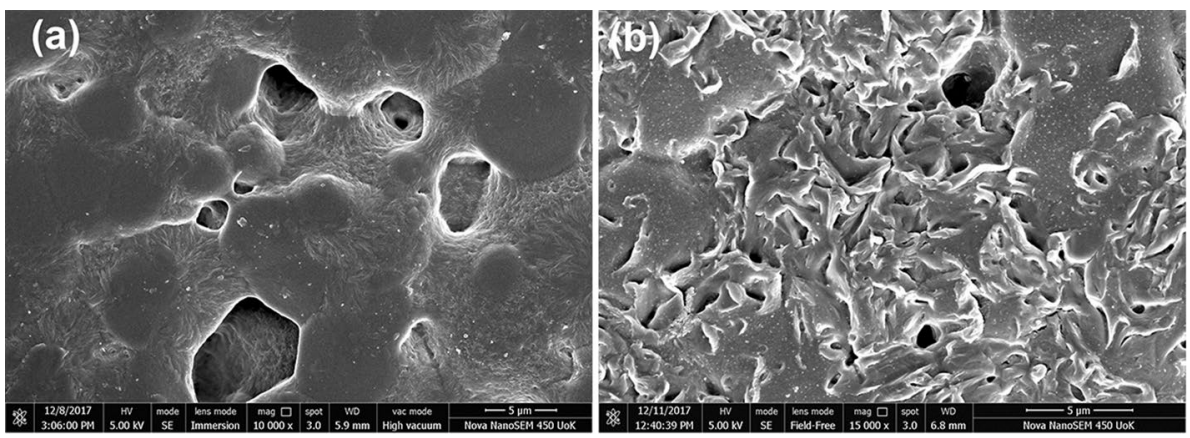
in PVDF/FSWCNT-4 composites. The functionalized nanotubes together with the effect of ultrasonication for a fixed time performed as an efficient heterogeneous nucleating agent by providing a large surface area for the crystallization of PVDF into scrolled lamellar like morphologies. Complementing our FESEM images, the AFM topography of PFSn-0.1-0 and PFSn-0.1-5 (Fig. 8a, b) show spherulites and scrolled lamellar features of $a$ and $y$ phases respectively. Thus, the rate of PVDF crystallization increases as a result of ultrasonication due to proper dispersion as well as interaction of FSWCNT-4 in the matrix.

Table 3 summarizes the mechanical properties of PVDF/ FSWCNT-4 composites ultrasonicated for different extent of time. Mechanical properties of neat PVDF (denoted as P-0) is also given for comparison. It is evident that for a fixed weight percentage $(0.1 \mathrm{wt} \%)$ of FSWCNT-4, there is dramatic change in the mechanical properties of PVDF composites when the time of ultrasonication is varied. Though the $\gamma$ phase content increases from 15 to $34 \%$ in PFSn-0.1-0 compared to $\mathrm{P}-\mathrm{0}$, the former shows the lowest modulus and tensile strength with the highest elongation attributed to agglomeration and inefficient dispersion of nanotubes. Young's modulus increases from $460 \mathrm{GPa}$ for P-0 to 1450 GPa (215\% increase) for the PVDF/FSWCNT-4 composite prepared with an ultrasonication time of $5 \mathrm{~min}$ (PFSn-0.1-5). On further increasing the time of ultrasonication, modulus is found to decrease progressively. Tensile strength also shows similar trend as that of Young's modulus with the highest strength shown by PFSn-0.1-5, which registers $154 \%$ increase compared to P-0. The weakening of the matrix with extent of ultrasonication is further evident in the elongation at break which is increasing with increase in the time of ultrasonication from 15 to $60 \mathrm{~min}$.

The mechanical properties of the PVDF/FSWCNT-4 demonstrate the influence of the processing parameter viz. ultrasonication and the effect of FSWCNT-4 in controlling the morphology of PVDF for imparting the modulus and strength to the polymer through phase changes. Since ultrasonication provides intense energy to the medium, the agglomerated nanotubes get apart thus enhancing its distribution in the polymer matrix and hence resulting in an efficient transfer of its properties to the PVDF matrix. This improves the mechanical properties of nanocomposites as observed for PFSn-0.1-5. However, at the same time, extending the time of ultrasonication induces damage both in the polymer and in the nanotube, resulting in lowering of properties which is observed for the nanocomposites ultrasonicated above $5 \mathrm{~min}$. Effect of ultrasonication on the mechanical properties of polycarbonate/carbon nanofiber composites has been reported by $\mathrm{He}$ et al. [31] where the experiments started from $1 \mathrm{~h}$ of sonication onwards. According to them, the optimum
Fig. 8 AFM topography of a PFSn-0.1-0 and b PFSn-0.1-5
Table 3 Mechanical properties of PVDF and PVDF/FSWCNT-4 composites ultrasonicated for different extent of time
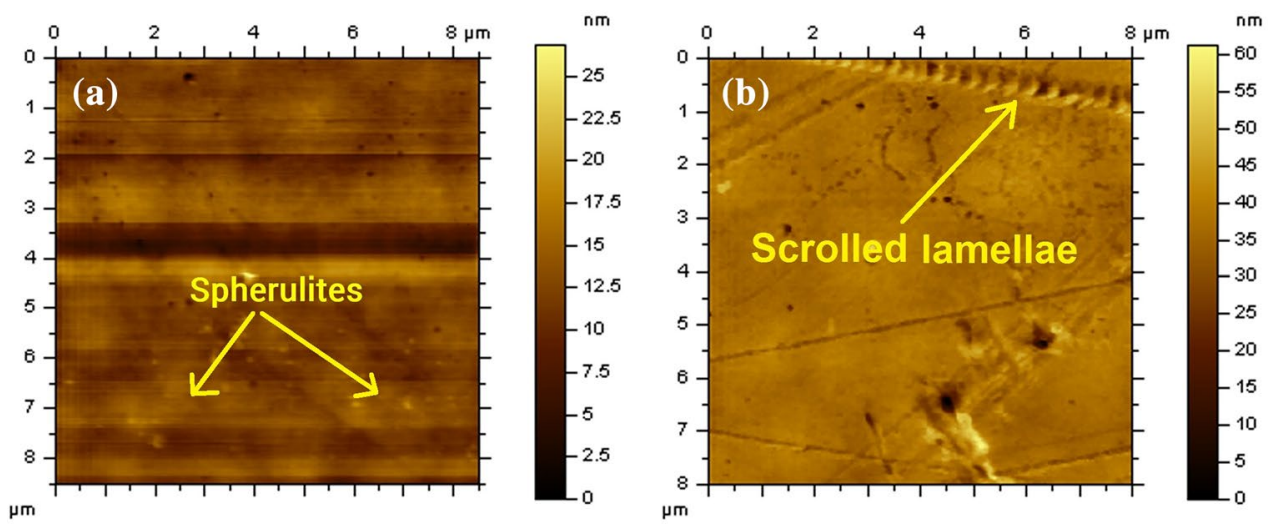

\begin{tabular}{llccc}
\hline Sample & $\begin{array}{l}\text { Percentage of } \gamma \\
\text { phase, } F_{\gamma}(\%)\end{array}$ & Modulus $(\mathrm{MPa})$ & $\begin{array}{l}\text { Tensile strength } \\
(\mathrm{MPa})\end{array}$ & $\begin{array}{l}\text { Elongation } \\
\text { at break (\%) }\end{array}$ \\
\hline P-0 & 15 & $460 \pm 5$ & $13.0 \pm 1.3$ & $7.1 \pm 0.02$ \\
PFSn-0.1-0 & 34 & $435 \pm 7$ & $11.0 \pm 1.1$ & $7.2 \pm 0.09$ \\
PFSn-0.1-5 & 95 & $1450 \pm 8$ & $33.0 \pm 2.2$ & $3.4 \pm 0.03$ \\
PFSn-0.1-15 & 78 & $880 \pm 6$ & $21.3 \pm 1.5$ & $4.7 \pm 0.02$ \\
PFSn-0.1-45 & 77 & $659 \pm 4$ & $17.4 \pm 0.6$ & $6.1 \pm 0.05$ \\
PFSn-0.1-60 & 72 & $644 \pm 3$ & $15.2 \pm 0.5$ & $6.9 \pm 0.04$ \\
PFSn-0.1-120 & 71 & $628 \pm 4$ & $14.7 \pm 0.3$ & $7.2 \pm 0.02$ \\
\hline
\end{tabular}


time of ultrasonication was $2 \mathrm{~h}$. Thus the present method is significantly less energy intensive method compared to the studies already reported [47]. Therefore, it can be concluded that both the incorporation of functionalized nanofiller into PVDF matrix and an efficient processing parameter result in the change in polymorphism of PVDF and brings about a stronger interaction between PVDF and FSWCNT-4 as confirmed from computational analysis. Both of these aspects play a key role in determining interesting changes in the mechanical properties. Hence, based on spectroscopic, morphological and mechanical property analysis, it is proved that $5 \mathrm{~min}$ is the optimum time of ultrasonication for PVDF/FSWCNT-4 composites to crystallize in maximum percentage of $\gamma$ phase.

\subsection{Effect of varying concentrations of FSWCNT-4 on the phase morphology and related properties of PVDF}

In the previous Section, it is found that $0.1 \mathrm{wt} \%$ of FSWCNT-4 cause's significant changes in the phase morphology and mechanical properties of PVDF and reduces the processing time to $5 \mathrm{~min}$ to get more than $90 \%$ y phase. In order to study the effect of concentration of FSWCNT-4 on the phase morphology and related properties of PVDF, PVDF/FSWCNT-4 composites were prepared by varying the FSWCNT-4 content in the order of $0.01 \mathrm{wt} \%, 0.05 \mathrm{wt} \%$ and $0.1 \mathrm{wt} \%$. Since $5 \mathrm{~min}$ is found to be the optimum time of ultrasonication, all these composites were processed by subjecting them to $5 \mathrm{~min}$ of ultrasonication followed by film casting and air drying. The identification of the different composites and the weight loading of FSWCNT-4 are given in Table 4. It is observed that loading of PVDF with FSWCNT-4 more than $0.1 \mathrm{wt} \%$ resulted in severe agglomeration and the films were not able to cast properly. Hence, the maximum weight loading has been limited to $0.1 \mathrm{wt} \%$.

FESEM images of the films given in Fig. 9 show that $\mathrm{P}-0$ is having a twisted lamellae type of morphology as observed by Layek et al. [48]. As can be seen in the image, PFSn-0.01-5 shows both scrolled lamellae as well as spherulitic crystals with the latter occupying the major portion. However, for PFSn-0.05-5 the scrolled lamellae occupied the major portion. On increasing the nanotube concentration to 0.1 , the spherulitic crystals disappeared completely and were occupied by the scrolled lamellar feature characteristic of $\gamma$ phase as observed by Vaughan et al. [45]. Thus, the presence of large number of functional groups on FSWCNT-4 provided more nucleation sites which increased the crystallization rate of PVDF. Further, on increasing the content of FSWCNT- 4 to $0.1 \%$, the morphology changed from spherulitic crystallite to scrolled lamellar morphology as observed for PFSn-0.1-5.
Table 4 Designated codes for PVDF/FSWCNT-4 composites with different weight loading of FSWCNT-4

\begin{tabular}{|c|c|}
\hline Identification of the films ${ }^{a}$ & $\begin{array}{l}\text { Concentration of } \\
\text { FSWCNT-4 (wt } \%)\end{array}$ \\
\hline PFSn-0.01-5 & 0.01 \\
\hline PFSn-0.05-5 & 0.05 \\
\hline PFSn-0.1-5 & 0.10 \\
\hline
\end{tabular}

${ }^{\text {ap }}$ denotes PVDF; FSn denotes functionalized SWCNT for $4 \mathrm{~h}$; all compositions have been ultrasonicated for $5 \mathrm{~min}$

Figure 10 shows the overlaid FTIR spectra of PVDF/ FSWCNT-4 composites containing varying amount of FSWCNT-4. FTIR results reveal that the phase conversion in PVDF depends on the concentration of FSWCNT-4 as well. Neat PVDF contains majority of non-polar a phase with absorbance peaks at 613,763, 795976 and $1208 \mathrm{~cm}^{-1}$. However, the characteristics peaks corresponding to a phase decreases in intensity or completely disappears in the composites filled with different weight loadings of FSWCNT-4. There is no appreciable change in the crystalline phase of PVDF with the addition of $0.01 \mathrm{wt} \%$ of FSWCNT-4 with a major phase observed as the non-polar a phase. On the other hand, as the nanotube concentration is increased to $0.05 \mathrm{wt} \%$, there is a decrease of the intensity of the peaks at $613,763,795$ and $976 \mathrm{~cm}^{-1}$ along with appearance of new peaks at 812,833 and $1234 \mathrm{~cm}^{-1}$ corresponding to the polar $\gamma$ phase. On further raising the FSWCNT-4 concentration to $0.1 \%$ results in almost complete nucleation of $\gamma$ phase. As already discussed, FSWCNT-4 loading beyond $0.1 \mathrm{wt} \%$ was not feasible in this study.

Analysis of FTIR spectra given in Fig. 10 shows that $-\mathrm{CF}_{2}$ stretching occurs at $1179 \mathrm{~cm}^{-1}$ in PVDF and it shows a negative shift with the addition of FSWCNT-4. This shift indicates interactions between $-\mathrm{CF}_{2}$ and $\pi$ electrons on the CNT surface. Similarly, as a sign of interaction between the functional groups of CNTs $(-\mathrm{COOH}$ and $-\mathrm{OH})$ and $-\mathrm{CF}_{2}$, the bending vibration of $-\mathrm{CF}_{2}$ in PVDF, which appears at $870 \mathrm{~cm}^{-1}$ is shifted to higher side in the composites [49]. These results confirm that the $y$ phase formation is driven through the interaction between carboxyl groups in FSWCNT with the methylene group in PVDF as confirmed from computational analysis (Fig. 4).

The electroactive phase content of PVDF incorporated with different weight percentage of FSWCNT-4 is calculated using Eq. (1). The variation of $\gamma$ phase content of PVDF and their composites are represented graphically as shown in Fig. 11. The percentage of $\gamma$ phase in $\mathrm{P}-0(15 \%)$ is increased to $95 \%$ in PFSn-0.1-5.

To further confirm the interaction in PVDF/FSWCNT-4 composites containing varying concentration of FSWCNT-4, Raman spectroscopy was employed and the 
Fig. 9 FESEM images of a P-0, b PFSn-0.01-5, c PFSn-0.05-5 and d PFSn-0.1-5. Scale bar is $5 \mu \mathrm{m}$ and magnification is $\times 10,000$
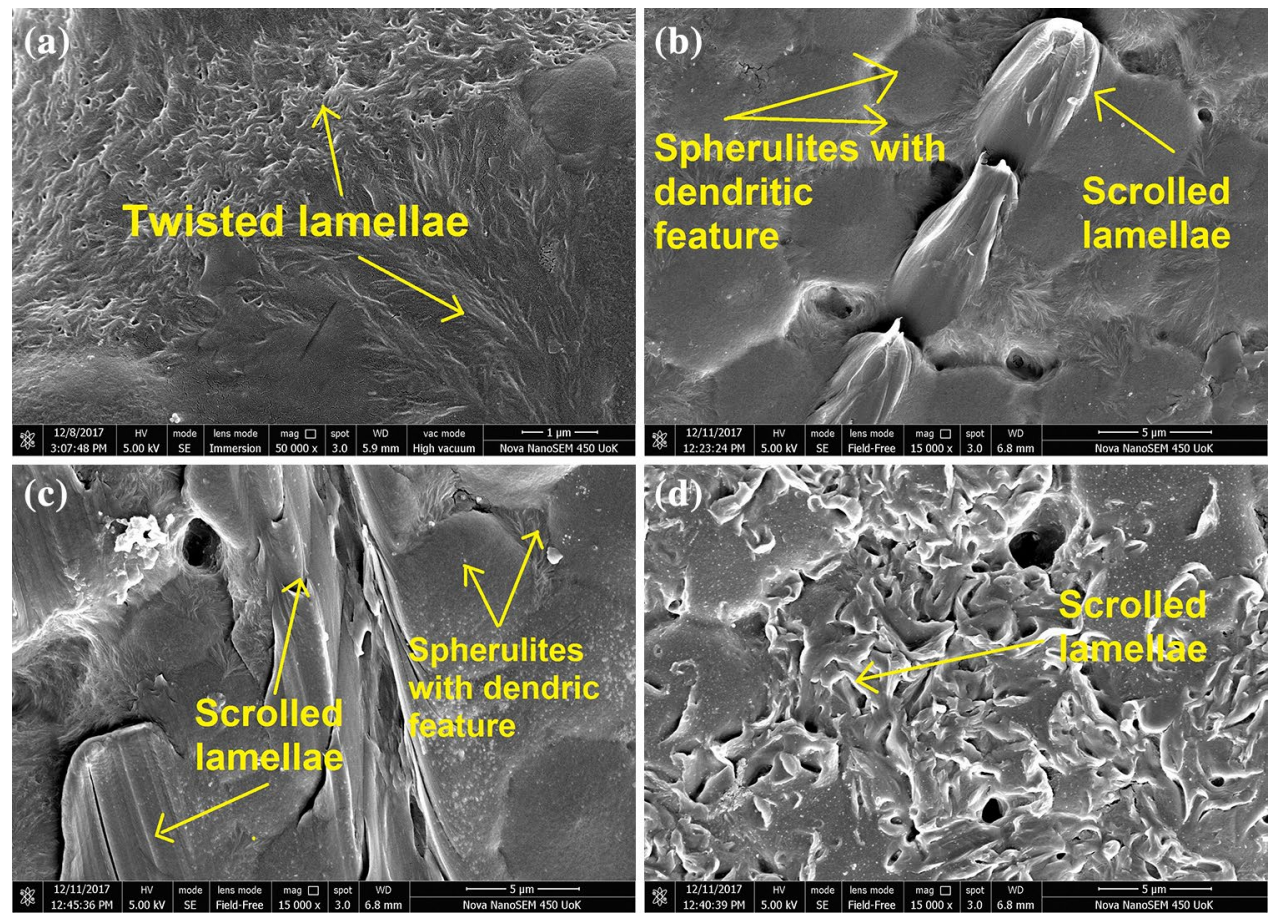

spectra are given in Fig. 12. The $G, D$ and $2 D$ band positions of FSWCNT-4 and the nanocomposites are shown in ESI. The G-band located at $1564 \mathrm{~cm}^{-1}$, the D-band at $1320 \mathrm{~cm}^{-1}$ and the $2 \mathrm{D}$ band at $2652 \mathrm{~cm}^{-1}$ show an upshift of $28 \mathrm{~cm}^{-1}, 15 \mathrm{~cm}^{-1}$ and $32 \mathrm{~cm}^{-1}$ respectively. As already discussed, the upshift of G, D and 2D band peaks proves an efficient contact between PVDF chain and FSWCNT-4.

In order to characterize the defects and impurities in CNTs, $I_{D} / I_{G}$ ratio (i.e. the ratio of intensities of D-band to the $\mathrm{G}$-band) is used $[50,51]$. The $\mathrm{I}_{\mathrm{D}} / \mathrm{I}_{\mathrm{G}}$ ratios of FSWCNT-4 and composites are given in ESI. After ultrasonication of nanotubes with PVDF matrix, the $\mathrm{I}_{\mathrm{D}} / \mathrm{I}_{\mathrm{G}}$ ratio increases with FSWCNT-4 content. For FSWCNT-4, $\mathrm{I}_{\mathrm{D}} / \mathrm{I}_{\mathrm{G}}$ was 0.08 which increased to $0.15,0.2$ and 0.23 respectively for $0.01,0.05$ and $0.1 \mathrm{wt} \%$ of FSWCNT-4 in PVDF matrix, further confirming the role of ultrasonication in inducing defects and leading to the shortening of nanotubes. Interestingly, the 2D band located at $2620 \mathrm{~cm}^{-1}$ also shows an upshift of $32 \mathrm{~cm}^{-1}$ due to the inhibition of the larger diameter metallic FSWCNT-4, resulting in a momentous transformation of their electronic states.

To understand the effects of FSWCNT-4 on the behaviour of PVDF crystallization, the polymer and the composites were subjected to crystallization studies using DSC. The heating thermograms of PVDF and the polymer loaded with different concentrations of FSWCNT-4 are shown in ESI. PVDF shows a characteristic melting temperature at $159.8^{\circ} \mathrm{C}$ which progressively increases on addition of FSWCNT-4. PFSn-0.1-5, which is having more than $90 \% \gamma$ phase, melts at $163.1^{\circ} \mathrm{C}$ confirming that a perfectly arranged polar phase requires higher temperature for melting to happen.

The corresponding cooling curves obtained from DSC analysis are given in ESI. The crystallization peak of PVDF was at $133.5^{\circ} \mathrm{C}\left(\mathrm{T}_{\mathrm{C}}\right)$, which infers the presence of a phase. However, upon addition of FSWCNT-4 into the PVDF matrix, a gradual shift in $\mathrm{T}_{C}$ to higher temperature was observed. $\mathrm{T}_{\mathrm{C}}$ for PFSn-0.1-5 increased to $139.1^{\circ} \mathrm{C}$, confirming that at a weight percentage of $0.1 \%$ FSWCNT-4, the crystallization of PVDF occurs with an ease. The presence of functional groups on FSWCNT-4 makes it to act as an efficient nucleating agent providing enormous surface area for an easier crystallization of PVDF.

To investigate the role of FSWCNT-4 in affecting the thermal stability of PVDF, TGA was carried out and the thermograms are shown in ESI. The value of peak decomposition temperature for PVDF and their nanocomposites are tabulated in Table 5. FSWCNT-4 plays a key role in enhancing the thermal stability of PVDF. The peak decomposition temperature is increased from 443 to $466^{\circ} \mathrm{C}$ with the incorporation of $0.01 \mathrm{wt} \%$ FSWCNT-4 in the matrix. However, there is no significant change in the peak decomposition temperature with increase in the FSWCNT-4 loading. With the addition of FSWCNT-4, the improvement in thermal stability is attributed to the perfectly arranged $\gamma$ phase crystallites in the nanocomposites [8].

The electrical properties of PVDF as well as their nanocomposites have a direct relationship with percentage of $\gamma$ phase [36]. Table 6 shows the dependence of capacitance 


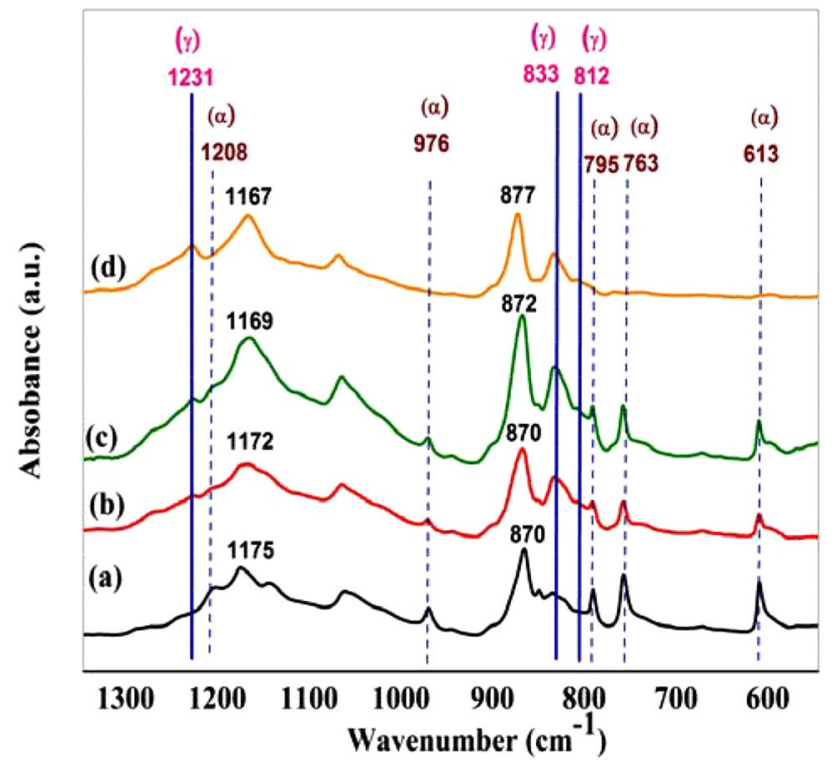

Fig. 10 Overlaid FTIR spectra of PVDF with different weight percentage of FSWCNT-4 prepared with an ultrasonication time of 5 min. (a) P-0, (b) PFSn-0.01-5, (c) PFSn-0.05-5 and (d) PFSn-0.1-5

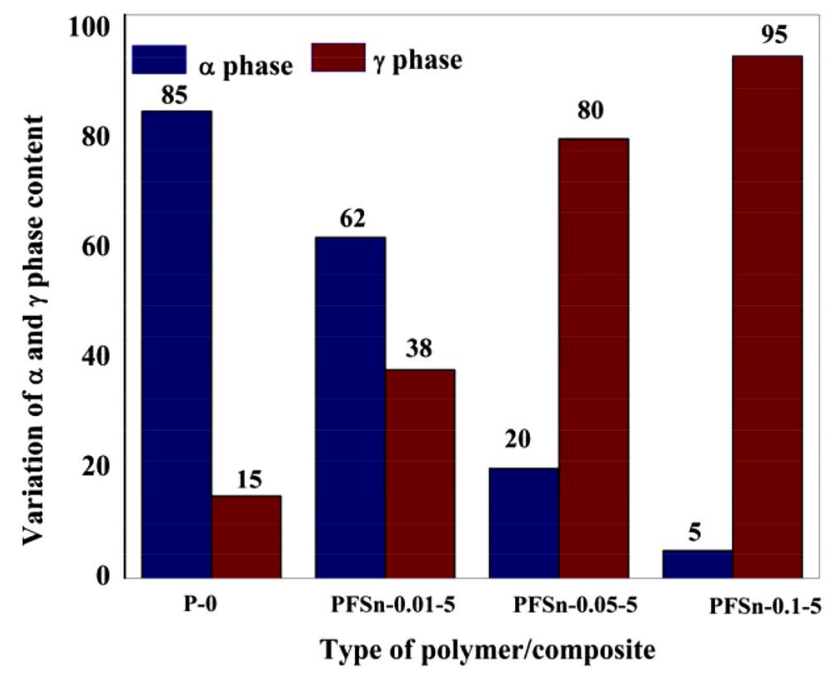

Fig. 11 Variation of $a$ and $\gamma$ phase content as a function of FSWCNT-4 concentration in PVDF matrix

of the films with the percentage of $\gamma$ phase for PVDF and PVDF/FSWCNT-4 composites. P- 0 with a percentage $\gamma$ phase fraction of 28 had a capacitance value of $150.6 \mathrm{pF}$. Addition of $0.1 \mathrm{wt} \%$ FSWCNT-4 in PVDF (PFSn-0.1-5) increases the capacitance to $326.9 \mathrm{pF}$ with an enhancement of $117 \%$ in comparison to P-0. These observations clearly indicate that the formation of $y$ phase in PVDF with the incorporation of $0.1 \%$ FSWCNT-4 is responsible for its enhanced electrical properties further validating the results of spectroscopy as well as morphological analyses.

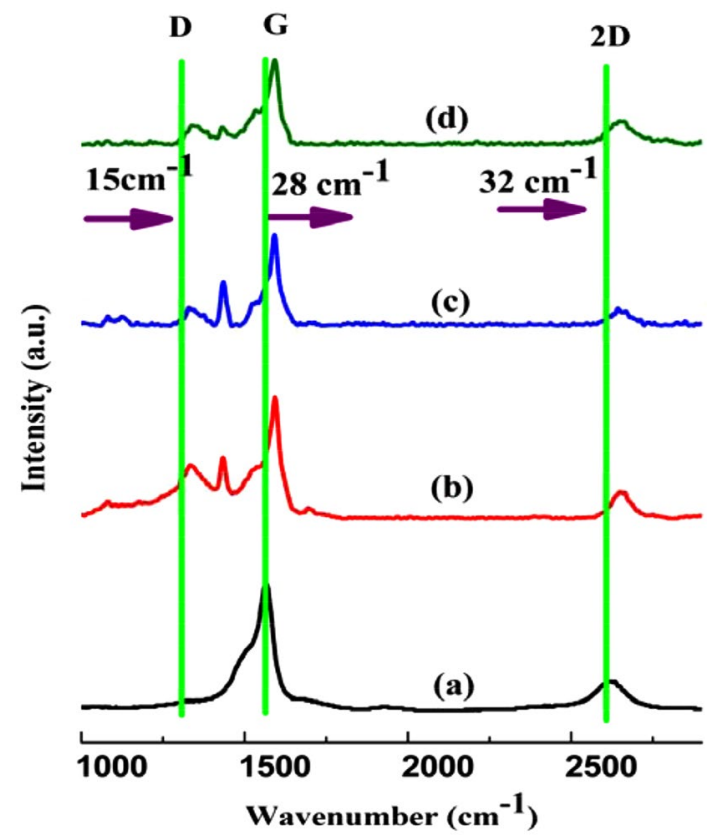

Fig. 12 Raman spectrum of (a) FSWCNT-4, (b) PFSn-0.01-5, (c) PFSn0.05-5, (d) PFSn-0.1-5 respectively

Table 5 Peak decomposition temperature for PVDF and PVDF/ FSWCNT-4 composites

\begin{tabular}{ll}
\hline Sample & $\begin{array}{l}\text { Peak decomposition } \\
\text { temperature }\left(T_{p}\right){ }^{\circ} \mathrm{C}\end{array}$ \\
\hline P-0 & 443.0 \\
PFSn-0.01-5 & 466.0 \\
PFSn-0.05-5 & 466.5 \\
PFSn-0.1-5 & 466.8 \\
\hline
\end{tabular}

Table 7 shows the changes in mechanical properties with different FSWCNT-4 concentrations in PVDF matrix. Young's modulus and tensile strength increase gradually with increase in FSWCNT-4 concentration. Composite with maximum $\gamma$ phase content has the highest mechanical properties, as is evident from the table.

The mechanical properties of PVDF and its various composites are explained with the help of morphology, nano-dispersion and structure-property relationships. Analysis of the morphology reveals that P-0 exhibits a twisted lamellar morphology with a polymorphic structure. PFSn-0.01-5 and PFSn-0.05-5 possesses a mixture of $a$ and $\gamma$ crystallites with a combination of spherulitic and scrolled lamellar morphologies while PFSn-0.1-5 has a fully $Y$ polymorphic structure with majority of scrolled lamellar crystallites. Thus morphological changes of PVDF with the incorporation of different concentrations of FSWCNT-4 directly relates to their mechanical properties. 
Table 6 Capacitance of PVDF and PVDF/FSWCNT-4 composites at $1 \mathrm{kHz}$

\begin{tabular}{lll}
\hline Sample & FY $(\%)$ & Capacitance in Pf \\
\hline P-0 & 15 & 150.6 \\
PFSn-0.01-5 & 38 & 196.2 \\
PFSn-0.05-5 & 80 & 272.5 \\
PFSn-0.1-5 & 95 & 326.9 \\
\hline
\end{tabular}

Table 7 Mechanical properties of PVDF and PVDF/FSWCNT-4 composites with different FSWCNT-4 content, as a function of $\gamma$ phase $(\mathrm{F} \gamma)$ in the polymer

\begin{tabular}{llcll}
\hline Sample & FY (\%) & Modulus (MPa) & $\begin{array}{l}\text { Tensile } \\
\text { strength } \\
(\mathrm{MPa})\end{array}$ & $\begin{array}{l}\text { Elongation } \\
\text { at break (\%) }\end{array}$ \\
\hline P-0 & 15 & $970 \pm 5$ & $25.0 \pm 1.3$ & $4.2 \pm 0.02$ \\
PFSn-0.01-5 & 38 & $980 \pm 4$ & $26.5 \pm 0.9$ & $4.0 \pm 0.01$ \\
PFSn-0.05-5 & 80 & $1033 \pm 6$ & $28.0 \pm 1.1$ & $3.9 \pm 0.02$ \\
PFSn-0.1-5 & 95 & $1450 \pm 8$ & $33.0 \pm 2.2$ & $3.4 \pm 0.03$ \\
\hline
\end{tabular}

At the same time, efficient interaction as well as dispersion of FSWCNT-4 in the PVDF matrix also contributes to the improvement of mechanical properties for these composites. The proper interaction of FSWCNT-4 is brought about by the optimized functionalization of nanotubes $(4 \mathrm{~h}$ in the present study) with maximum amount of functional groups on the nanotube surface. Efficient dispersion of FSWCNT-4 in PVDF matrix is accounted by effective processing through ultrasonication for 5 min which induces maximum crystalline phase and minimum induced defects in FSWCNT-4. Both these factors contribute to a stronger interaction between $\mathrm{H}$ atom with positive charge in PVDF and "O" atom with $\pi$ orbital in FSWCNT as confirmed from computational analysis.

\section{Conclusions}

In this paper, the dependence of duration of ultrasonication as well as different concentrations of optimally functionalized SWCNT (FSWCNT-4) on the morphology, polymorphism and physical properties of PVDF composites have been studied. Composite with almost $95 \%$ y phase is produced by tuning the time of ultrasonication to $5 \mathrm{~min}$ using $0.1 \%$ FSWCNT- 4, which also displays the highest electrical and mechanical properties. Pure PVDF (P-0) show twisted lamellar feature characteristics of a phase morphology whereas 0.01 and $0.05 \mathrm{wt} \%$ of FSWCNT-4 in PVDF matrix (PFSn-0.01-5 and PFSn-0.05-5) show mixture of twisted lamellar and scrolled lamellar features characteristics of $a$ and $\gamma$ phases. However, addition of $0.1 \%$
FSWCNT-4 in PVDF matrix (PFSn-0.1-5) gives fully scrolled lamellar features of polar $\gamma$ phase. The crystallization of pure $Y$ phase is further confirmed by FTIR, Raman, DSC and TGA measurements. The incorporation of FSWCNT-4 in PVDF matrix was confirmed from XPS. Electrical properties increase with increasing $\gamma$ phase content with PFSn$0.1-5$ showing an increase of $117 \%$ in comparison to neat PVDF. Mechanical property measurements show that the tensile strength and modulus increase with filler loading and $\gamma$ phase content where PFSn-0.1 show an enhancement up to $32 \%$ in tensile strength and $50 \%$ in modulus in comparison to neat PVDF. Realization of superior electrical and mechanical properties proves that the nanocomposite prepared using FSWCNT-4 is a promising system, which is attributed to a stronger interaction between $\mathrm{H}$ atom with positive charge in PVDF and "O" atom with $\pi$ orbital in FSWCNT-4 as confirmed by computational analysis. This study explores the possibility of using optimally functionalized SWCNT (FSWCNT-4) as an effective filler in imparting predominantly $\gamma$ phase by means of minimal process conditions (5 min ultrasonication) for the production of PVDF-SWCNT composites for various applications.

Acknowledgements The authors are very much thankful to the Director, Vikram Sarabhai Space Centre (VSSC) for permission to publish this work. All colleagues in Polymers and Special Chemicals Division as well as Analytical and Spectroscopy Division, VSSC are also acknowledged for their support. One of the authors (Rinu Elizabeth Roy) is thankful to Indian Space Research Organization (ISRO) for the research fellowship.

\section{Compliance with ethical standards}

Conflict of interest On behalf of all authors, the corresponding author states that there is no conflict of interest.

\section{References}

1. Roy RE, Soundiraraju B, Thomas D, Balachandran N, Ambika C, Rajeev RS (2017) New insights into the spectral, thermal and morphological analysis of time dependent structural changes during open end functionalization of single walled carbon nanotubes. New J Chem 41:12159

2. Roy RE, Vijayalakshmi KP, Rajeev RS (2019) Importance of optimization of functionalization of single walled carbon nanotube with special reference to mechanical, viscoelastic and adhesive characteristics of vinyl terminated polydimethyl siloxane. Polymer 160:181

3. Roy RE, Vijayalakshmi KP, Soumyamol PB, Rajeev RS (2019) Fluorosilicone polymers with tailored mechanical, acid resistant and adhesive properties: role of ultrasonication and functionally active single walled carbon nanotubes. Mater Chem Phys 223:523

4. Konishi Y, Cakmak M (2006) Nanoparticle induced network selfassembly in polymer carbon black composites. Polymer 47:5371

5. Xu HP, Dang ZM (2007) Electrical property and microstructure analysis of poly(vinylidene fluoride)-based composites with different conducting fillers. Chem Phys Lett 438:196 
6. Chen GX, Li Y, Shimizu H (2007) Ultrahigh-shear processing for the preparation of polymer/carbon nanotube composites. Carbon 45:2334

7. Costa P, Silva J, Sencadas V, Costa CM, van-Hattum FWJ, Rocha JG, Mendez SL (2009) The effect of fibre concentration on the a to $\beta$-phase transformation, degree of crystallinity and electrical properties of vapour grown carbon nanofibre/poly(vinylidene fluoride) composites. Carbon 47:2590

8. Manna S, Nandi AK (2007) Piezoelectric polymorph in poly (vinylidene fluoride) - functionalized multiwalled carbon nanotube nanocomposite films. J Phys Chem C 111:14670

9. Dang ZM, Wang L, Yin Y, Zhang Q, Lei QQ (2007) Giant dielectric permittivities in functionalized carbon-nanotube/electroactivepolymer nanocomposites. Adv Mater 19:852

10. Chen D, Wang M, Zhang WD, Liu T (2009) Preparation and characterization of poly (vinylidene fluoride) nanocomposites containing multiwalled carbon nanotubes. J Appl Polym Sci 113:644

11. Layek RK, Samanta S, Chatterjee DP, Nandi AK (2010) Physical mechanical properties of poly (methyl methacrylate)-functionalized graphene-poly(vinylidene fluoride) nanocomposites: piezoelectric polymorph formation. Polymer 51:5846

12. Levi N, Czerw R, Xing SY, Lyer P, Carroll DL (2004) Properties of polyvinylidene difluofide-carbon nanotube blends. Nano Lett 4:1267

13. Yu S, Zheng W, Yu W, Zhang Y, Jiang Q, Zhao Z (2009) Formation Mechanism of $\beta$-phase in PVDF/CNT composite prepared by the sonication method. Macromolecules 42:8870

14. Qu T, Pan K, Li L, Liang B, Wang L, Cao B (2014) Influence of ultrasonication conditions on the structure and performance of poly(vinylidene fluoride) membranes prepared by the phase inversion method. Ind Eng Chem Res 53:8228

15. Doktycz SJ, Suslick KS (1990) Interparticle collisions driven by ultrasound. Science 247:1067

16. He L, Sun J, Zheng X, Xu Q, Song R (1905) Effect of multiwalled carbon nanotubes on crystallization behavior of poly(vinylidene fluoride) in different solvents. J Appl Polym Sci 119:2011

17. Hong SM, Seo $Y$ (2009) Piezoelectric properties of poly(vinylidene fluoride) and carbon nanotube blends: $\beta$-phase development. Phys Chem Chem Phys 11:10506

18. Vukicevic R, Vukovic I, Stoyanov H, Korwitz AA, Pospiech D, Kofod G, Loos K, Brinke G, Beuermann S (2012) Poly(vinylidene fluoride)-functionalized single-walled carbon nanotubes for the preparation of composites with improved conductivity. Polym Chem 3:2261

19. Matea A, Baibarac M, Baltog I (2017) Optical properties of singlewalled carbon nanotubes highly separated in semiconducting and metallic tubes functionalized with poly(vinylidene fluoride). J Mol Struct 1130:38

20. Tao MM, Liu F, Xue LX (2013) Poly (vinylidene fluoride) membranes by an ultrasound assisted phase inversion method. Ultrason Sonochem 20:232

21. Achabya ME, Arrakhiza FZ, Vaudreuila S, Essassia EM, Qaissa A (2012) Piezoelectric polymorph formation and properties enhancement in graphene oxide: PVDF nanocomposite films. Appl Surf Sci 258:7668

22. Benz M, Euler WB (2003) Determination of the crystalline phases of poly(vinylidene fluoride) under different preparation conditions using differential scanning calorimetry and infrared spectroscopy. J Appl Polym Sci 89:1093

23. Lopes AC, Caparros C, Gomez Ribelles JL, Neves IC, LancerosMéndez S (2012) Electrical and thermal behavior of gammaphase poly(vinylidene fluoride)/NaY zeolite composites. Microporous Mesoporous Mater 161:98

24. Bachilo SM, Strano MS, Kittrell C, Hauge RH, Smalley RE, Weisman RB (2002) Structure-assigned optical spectra of singlewalled carbon nanotubes. Science 298:2361
25. Stewart JJ (2007) Optimization of parameters for semiempirical methods V: modification of NDDO approximations and application to 70 elements, elements. J Mol Model 13:1173

26. Frisch MJ, Trucks GW, Schlegel HB, Scuseria GE, Robb MA, Cheeseman JR et al (2009) Gaussian_09 revision. Gaussian, Wallingford

27. Kobayashi M, Tashiro K, Tadokoro H (1975) Molecular vibrations of three crystal forms of poly(vinylidene fluoride). Macromolecules 8:158

28. Ince-Gunduz BS, Alpern R, Amare D, Crawford J, Dolan B, Jones S, Kobylarz R, Reveley M, Cebe P (2010) Impact of nanosilicates on poly (vinylidene fluoride) crystal polymorphism: part 1. Meltcrystallization at high supercooling. Polymer 51:1485

29. Roy RE, Soundiraraju B, Vijayalakshmi KP, Dimple R, Soumyamol PB, Rajeev RS (2019) Energy induced polymorphic changes in poly(vinylidene fluoride): how ultrasonication results in polymer with predominantly $Y$ phase. J Polym Sci B Polym Phys 57:40

30. Lopes AC, Costa CM, Tavares CJ, Neves IC, Lanceros-Mendez $S$ (2011) Nucleation of the electroactive $Y$ phase and enhancement of the optical transparency in low filler content poly(vinylidene)/clay nanocomposites. J Phys Chem C 115:18076

31. He P, Gao Y, Lian J, Wang L, Qian D, Zhao J, Wang W, Schulz MJ, Zhou XP, Shi D (2006) Surface modification and ultrasonication effect on the mechanical properties of carbon nanofiber/polycarbonate composites. Compos A 37:1270

32. Hattori T, Masamichi H, Ohigashi H (1996) The crystallization behaviour and phase diagram of extended-chain crystals of poly(vinylidene fluoride) under high pressure. Polymer 37:85

33. Chang X, Wang Z, Quan S, Xu Y, Jiang Z, Shao L (2014) Exploring the synergetic effects of graphene oxide $(\mathrm{GO})$ and polyvinylpyrrodione (PVP) on poly (vinylidinefluoride) (PVDF) ultrafiltration membrane performance. Appl Surf Sci 316:537

34. Zhao C, Lv J, Xu X, Zhang G, Yang Y, Yang F (2017) Highly antifouling and antibacterial performance of poly(vinylidinefluoride) ultrafiltration membranes blending with copper oxide and graphene oxide nanofillers for effective wastewater treatment. J Colloid Interface Sci 505:341

35. Zhao C, Xu X, Chen J, Wang G, Yang F (2014) Highly effective antifouling performance of PVDF/graphene oxide composite membrane in membrane bioreactor (MBR) system. Desalination 340:59

36. Thomas E, Chandrababu PC, Balachandran N, Soundiraraju B, Vijayalakshmi KP, George BK (2017) PVDF-ionic liquid modified clay nanocomposites: phase changes and shish-kebab structure. Polymer 115:7

37. Owens JF, Jayakody JRP, Greenbaum SG (2006) Characterization of single walled carbon nanotube: polyvinylene difluoride composites. Compos Sci Technol 66:1280

38. Nish A, Hwang JY, Doig J, Nicholas RJ (2007) Highly selective dispersion of single-walled carbon nanotubes using aromatic polymers. Nat Nanotechnol 2:640

39. Rice NA, Soper K, Zhou N, Merschrod E, Zhao Y (2006) Dispersing as-prepared single-walled carbon nanotube powders with linear conjugated polymers. Chem Commun 47:4937

40. Freiman S, Hooker S, Migler K, Arepalli S (2008) Measurement issues in single wall carbon nanotubes. National Institute of Standards and Technology, USA

41. Rao AM, Eklund PC, Bandow S, Thess A, Smalley RE (1997) Evidence for charge transfer in doped carbon nanotube bundles from Raman scattering. Nature 388:257

42. Ye M, Qiu ZJ, Li H, Qu M, Liu R (2014) Preferential interaction of small-diameter metallic SWNTs with ferroelectric polymer. RSC Adv 4:19658

43. Mandal A, Nandi AK (2012) Noncovalent functionalization of multiwalled carbon nanotube by a polythiophene-based 
compatibilizer: reinforcement and conductivity improvement in poly (vinylidene fluoride) films. J Phys Chem C 116:9360

44. Remskar M, Iskra I, Jelenc J, Skapin SD, Visic B, Varlec A, Krzan A (2013) Novel structure of polyvinylidene fluoride (PVDF) stabilized by $\mathrm{MoS}_{2}$ nanotubes. Soft Matter 9:8647

45. Vaughan AS (1805) Etching and morphology of poly(vinylidene fluoride). J Mater Sci 28:1993

46. Holland VF, Miller RL (1964) Isotactic polybutene-1 single crystals: morphology. J Appl Phys 35:3241

47. Peng B, Wu H, Bao W, Guo S, Chen Y, Huang H, Chen H, Lai SY, Jow $J$ (2011) Effects of ultrasound on the morphology and properties of propylene-based plastomer/nanosilica composites. Polym J 43:91

48. Layek RK, Das AK, Park MJ, Kim NH, Lee JH (2015) Enhancement of physical, mechanical, and gas barrier properties in non-covalently functionalized graphene oxide/poly(vinylidene fluoride) composites. Carbon 81:329
49. Xing C, Zhao M, Zhao L, You J, Cao X, Li Y (2013) lonic liquid modified poly (vinylidene fluoride): crystalline structures, miscibility, and physical properties. Polym Chem 4:5726

50. Kitamura H, Sekido M, Takeuchi H, Ohno M (2011) The method for surface functionalization of single-walled carbon nanotubes with fuming nitric acid. Carbon 49:3851

51. Kelarakis A, Hayrapetyan S, Ansari S, Fang J, Estevez L, Giannelis EP (2010) Clay nanocomposites based on poly(vinylidene fluoride-co-hexafluoropropylene): structure and properties. Polymer 51:469

Publisher's Note Springer Nature remains neutral with regard to jurisdictional claims in published maps and institutional affiliations. 